\title{
Otoplastic Surgery for Calcified Auricular Deformity
}

\author{
Ji hyung Lim* (iD, Jae Sang Han* ${ }^{*}$, Yeonji Kim ${ }^{(\mathbb{D}}$, and Shi Nae Park \\ Department of Otorhinolaryngology-Head and Neck Surgery, Seoul St. Mary's Hospital, College of Medicine, \\ The Catholic University of Korea, Seoul, Korea
}

\author{
이개 성형술을 통한 석회화 된 이개 변형 치료 \\ 임지형* · 한재상* · 김연지 · 박시내 \\ 가톨릭대학교 의과대학 서울성모병원 이비인후-두경부외과학교실
}

\author{
Received August 10, 2021 \\ Revised October 6,2021 \\ Accepted October 26, 2021 \\ Address for correspondence \\ Shi Nae Park, MD, PhD \\ Department of Otorhinolaryngology- \\ Head and Neck Surgery, \\ Seoul St. Mary's Hospital, \\ College of Medicine, \\ The Catholic University of Korea, \\ 222 Banpo-daero, Seocho-gu, \\ Seoul 06591, Korea \\ Tel +82-2-2258-6215 \\ Fax +82-2-595-1354 \\ E-mailsnparkmd@catholic.ac.kr \\ *These authors contributed equaly \\ to this work.
}

Auricular hematoma is one of the most common problems among people who have got repetitive blunt trauma to the external ear. Prompt managements are drainage of hematoma and following prevention of re-accumulation (e.g. compression dressing). If the treatment is not successful, many complications can occur, including perichondritis, infection and necrosis. Especially long-lasting loss of blood supply to the ear cartilage and formation of neocartilage from disrupted perichondrium can result in cauliflower ear deformity. There were some studies trying to classify and to treat the cauliflower ear by the degree of deformities. And excision of deformed cartilage with reshaping of the auricle has been reported several times. In this article, we would like to introduce a successful drilling technique of otoplasty as a useful treatment option.

Korean J Otorhinolaryngol-Head Neck Surg 2021;64(11):851-4

\section{서 론}

이개는 태생 4-5주에 6개의 융기에 의해 형성되는 기관으 로, 크기나 모양에 따라 다양한 인상을 줄 수 있기 때문에 미용적인 측면에서 중요한 의미를 갖는다. 그리고 머리에서 가장 튀어나와 있는 해부학적 구조로 인해 외상에 매우 취약 한 부위이기도 하다. ${ }^{1)}$

외이가 충격을 받게 되면 연골과 연골 막 사이에 혈종이 고 이게 되고, 통증을 유발하게 되는데, 이러한 급성기 외상에서 는 즉각적인 혈종 배액과 압박 드레싱 등이 먼저 시행되어야 한다. 그러나 치료가 불충분하거나 성공적이지 못한 경우 연

This is an Open Access article distributed under the terms of the Creative Commons Attribution Non-Commercial License (https://creativecommons.org/licenses/by-nc/4.0) which permits unrestricted non-commercial use, distribution, and reproduction in any medium, provided the original work is properly cited.
골막과 연골 사이에 감염, 염증 반응, 연골 염, 피부 괴사 등이 일어나게 되어 결국 그 부위에 석회화를 동반하는 새로운 연 골이 만들어지고, 양배추 귀(cauliflower ear)라 불리는 외이 의 변형이 생기게 된다. ${ }^{2,3)}$

이개 혈종으로 인해 외형적인 변형이 생긴 경우 수술적 치 료를 고안해 볼 수 있고 이개 변형의 정도에 따라 그 범위와 방법들을 달리 적용시킬 수 있다. 현재까지 일반적으로 사용 하는 수술적 방법은 변형된 외이의 연골 부위를 직접 절개하 여 모양을 바로잡는 외이성형술이 선택되어 왔으나, 이러한 적극적인 절개법은 수술 후 반흔이 많이 남는 단점이 있어 수 술 후 외이 모양에 대한 만족도가 낮다는 한계점이 있었다.")

저자들은 이러한 방법을 보완하여 최소 절개 후 피부 피판 을 올린 뒤 석회화 된 연골조직을 드릴링을 이용하여 얇게 모 양을 만들어 바로잡고, 이후 실리콘 몰딩(silicon molding) 방 
법을 활용하여 압박 드레싱을 시행하는 방법으로 만족할 만 한 수술 결과를 얻었다. 이에 이개 혈종 후 변형된 이개에 대 한 이개 성형술에 대해 본 술식과 결과를 소개하고자 한다.

\section{방 법}

\section{마취 및 환자 자세}

수술은 국소마취하에 진행하며, 환자의 선호에 따라 전신 마취도 가능하다. 일반적인 이과 수술과 마찬가지로 바로 누 운 자세에서 머리를 수술 부위 반대측으로 돌리도록 한다. 이 후 $1 \%$ 리도카인 및 1:100000 에피네프린 혼합액을 병변 주 위와 후이개에 주입하고 10 분 정도 기다린다.

\section{절개선 도안 및 접근}

변형된 연골 부위의 피부를 직접 절개할 경우 반흔이 두드 러지는 단점이 있기 때문에 가능한 눈에 띄지 않는 절개선을 만들기 위해 이륜(helix) 내부를 따라 약 1-2 cm가량의 최소 절개(minimal incision)를 도안한다. 이후 연골이 손상되지 않게 조심하면서 15 번 수술용 메스를 사용하여 피부를 얇게 절개한다(Fig. 1A). 이후 절개선을 통해 연골막(perichondri$\mathrm{um)} \mathrm{아래로} \mathrm{조직을} \mathrm{박리해} \mathrm{가며} \mathrm{피판을} \mathrm{올려} \mathrm{석회화가} \mathrm{심한}$ 연골 부위를 모두 노출시킨다(Fig. 1B).

\section{석회화된 연골 제거}

보조자가 Senn 견인기(Senn retractor)를 이용하여 시야를 확보하고 석회화된 연골을 미세 현미경 시야에서 1-4 mm 다 이아몬드 버어(diamond burr)를 이용하여 드릴하여 연골 부 위를 충분히 얇고 유연하게 만들어 변형된 이개 모양을 정상 적으로 교정한다. 드릴링 중간에 피부를 재위치 시킨 다음 이 개의 외관을 관찰하고 연골의 유연성을 만져가면서 확인하는 것이 좋다. 드릴링 과정에서 거상한 피부 조직의 버어에 의한 손상을 예방하기 위한 알루미늄 시트나 얇은 실라스틱 시트 (silastic sheet)를 연골과 피부 피판 사이에 위치시키는 것이 도움이 된다(Fig. 1C).

\section{봉합 및 트리암시놀론 주입}

생리식염수로 수술 부위를 충분히 세척하고 지혈한 후 피 부를 black silk 4-0을 이용하여 단순 봉합한다(Fig. 1D). 이 후 혈종 및 부종의 발생 가능성을 최소화하기 위해 triamcinolone (40 mg을 생리식염수 $4 \mathrm{~mL}$ 와 mix하여 사용)을 절 개 부위를 통해 연골과 피판 사이에 2-3 cc를 주입한다(Fig. 1E). 이후 봉합 부위에 Steri-Strip ${ }^{\mathrm{TM}}\left(3 \mathrm{M}^{\mathrm{TM}}\right.$, Saint Paul, MN, $\mathrm{USA}$ )로 보강하고, 방수 드레싱을 하여 오염을 방지한다.

\section{압박 드레싱}

기존 알려진 덴탈롤이나 탐폰 등을 이용한 압박 드레싱 (tie-through compression suture)은 정기적으로 드레싱을
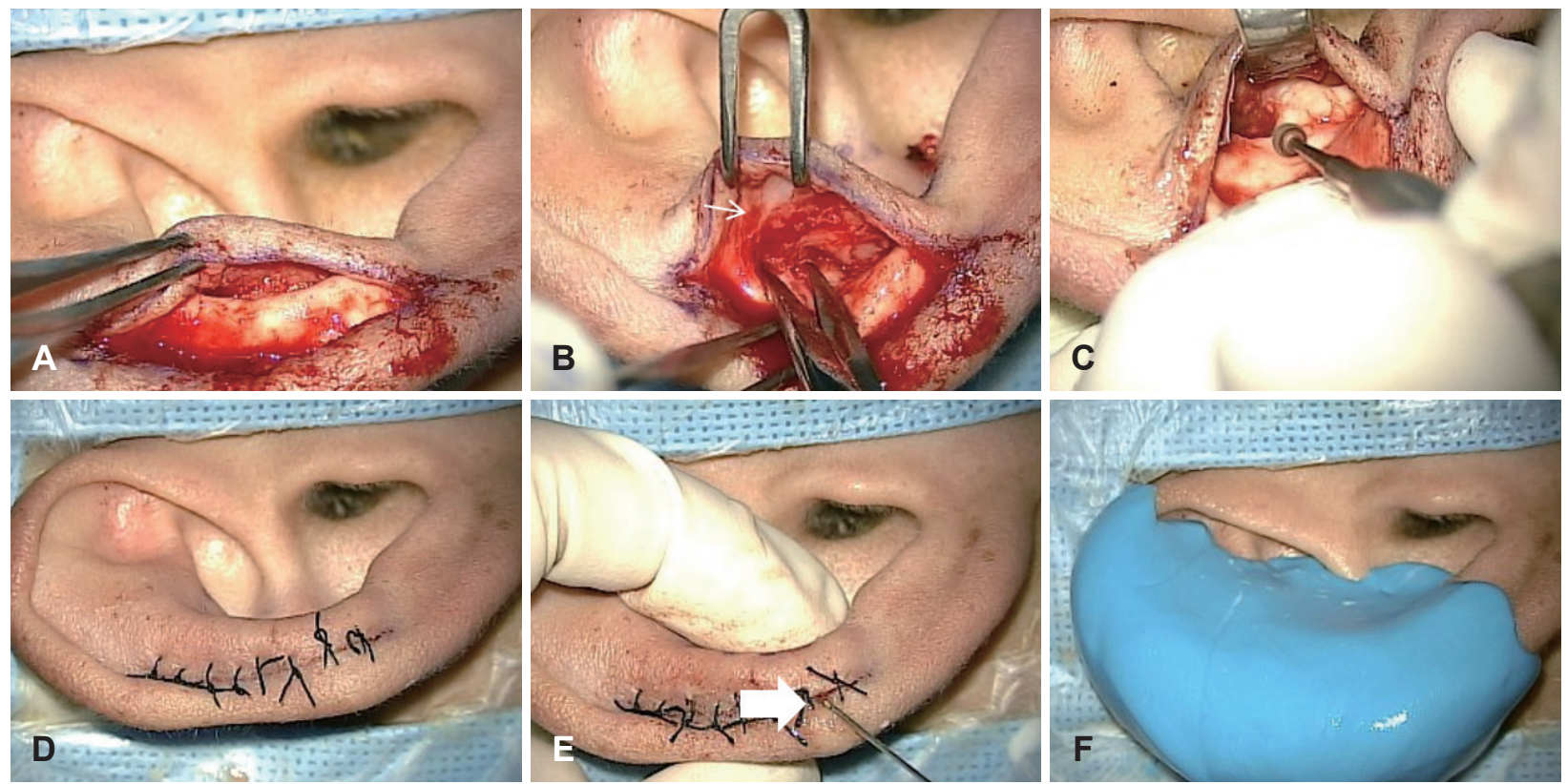

Fig. 1. Surgical procedures of otoplastic surgery for deformed and calcified auricle. A and B: Minimal longitudinal incision along the inner surface of the helix (A) and flap elevation to the calcified area of the auricle (B). C: Drilling of calcified cartilage with diamond burr under surgical microscope. D-F: Skin suture with 4-0 black silk (D), triamcinolone injection into operation site via incision margin (E, arrow) and compression dressing with silicone mold $(F)$. 
받아야하는 불편함이 있으므로 실리콘 몰드를 이용하여 수 술 부위를 압박한다. 몰딩에 사용되는 실리콘은 보청기 주조 시 사용하는 물질을 이용하는데, 실리콘과 경화제를 동량 섞 어 반죽한 다음 이개의 모양에 맞추어 압박된 상태에서 굳을 수 있도록 한다(Fig. 1F). 이후 실리콘 몰딩은 종이 플라스터 를 이용하여 고정한다.

\section{수술 후 관리}

환자에게 이개 통증이 심해질 경우 즉시 내원하도록 교육 하고 압박 드레싱은 2-3주간 유지한다. 수술 후 1주일째 외래 방문 시 수술 부위 확인 및 봉합사를 제거하고 실리콘을 교 체하여 1 주일간 더 유지하도록 한다.

\section{결 과}

외상 후 발생한 양측 이개 혈종이 반복될 경우(Fig. 2A and D), 이개가 전반적으로 두껍고 딱딱해지는 변형이 발생
할 수 있다(Fig. 2B and E). 이런 경우 미용적 문제뿐 아니라, 눕거나 만질 때 이개의 통증이 발생할 수 있으므로 수술적 치료를 고려해야 한다. 저자들이 소개한 수술 방법은 기존 방 법에 비해 수술 후 흉터가 거의 보이지 않을 정도로 미용적으 로 훌륭한 결과를 얻을 수 있으며, 석회화된 연골조직을 최 대한 제거하고 부드러운 연골조직만 남겨놓아 기능적으로도 만족할 수 있어 환자의 만족도가 높다(Fig. 2C and F). 미세 현미경 시야로 수술을 진행할 경우 석회화 조직과 정상 연골 조직을 육안으로 구분할 수 있어 수술의 정확도를 높일 수 있 으며, 이륜 내면을 따라 최소한의 절개를 가함으로써 미용적 으로 우수한 결과를 기대할 수 있다. 다이아몬드 버어를 이 용하여 드릴하는 방법은 거상된 피판이나 연골조직의 의도 하지 않은 손상을 최소화 하면서 석회화 된 부위만 세밀하게 제거할 수 있다는 장점이 있다.

수술 마지막 단계에는 약 2-3 cc의 triamcinolone을 절개 부위를 통해 피부 피판 아래에 주입하였고, 실리콘 몰드를 이 용한 압박 드레싱을 통해 실이나 거즈, 압박 붕대를 활용하
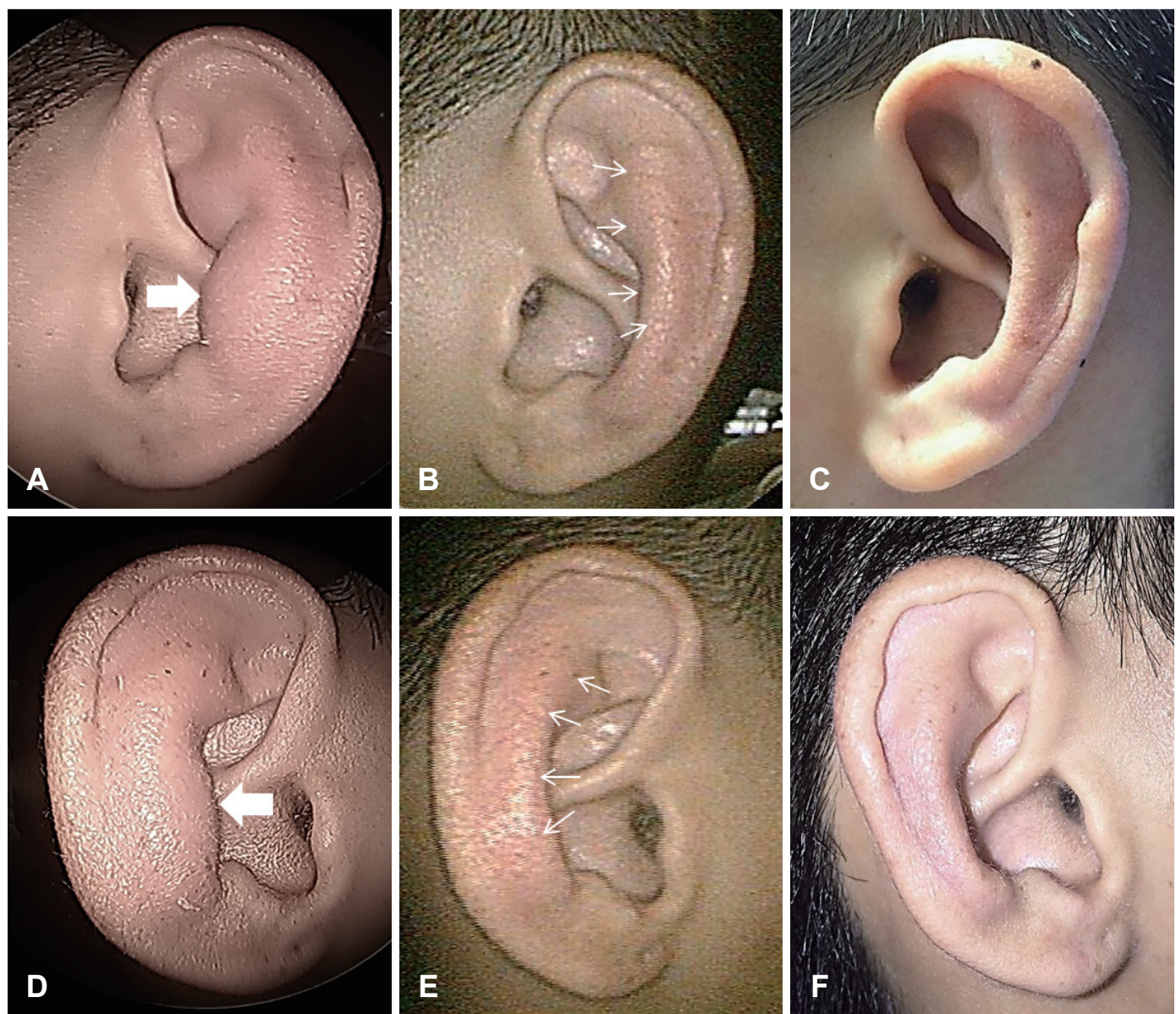

Fig. 2. Pictures of bilateral auricles at each stage in one patient. Otohematoma of the bilateral auricles ( $A$ and $D$, thick arrows) were treated with triamcinolone injection. Bilateral calcified and thick auricular deformities (B and $\mathrm{E}$, thin arrows) were occurred due to repeated trauma of the auricles, and the patient complained of pain when lying down. The postoperative pictures show normal looking thin and flexible auricles at 4 months after the surgery ( $\mathrm{C}$ and $\mathrm{F})$. 
는 기존의 압박 방법을 대체함으로써 편리성을 높였다. 이개 성형술 이후 수술 부위의 국소 스테로이드 주입술은 보편적 으로 보고된 방법은 아니지만 이개혈종의 치료법으로 보고된 바 있으며, 스테로이드의 혈관수축 작용을 통해 혈관 외 유출 을 줄일 수 있기 때문에 이개 혈종 재발을 낮추는 것으로 알 려져 있다. ${ }^{5)}$ 따라서 스테로이드가 피판을 거상한 부위 내부로 삼출액이 다시 생기는 것을 예방할 수 있을 것으로 생각되어 저자들은 이개 연골의 노출이 크고 추가적인 혈종 및 부종의 발생 가능성이 높은 수술 부위에 사용하고 있다. 스테로이드 용액은 봉합 부위로 일부 누출될 수 있기 때문에 압박 드레 싱의 효과를 낮추지는 않을 것으로 생각되며, 피판 아래에 도 포되는 것만으로도 충분한 효과를 얻을 수 있을 것으로 생 각한다.

미용적 측면을 고려하여 최대한 노출이 적은 이륜 내면을 따라 최소한의 절개를 통해 병변부에 접근하는 본 술식은 이 개 병변의 위치와 크기에 따라 절개의 위치와 크기를 달리할 수 있겠으나 이개혈종 이후 발생한 이개 전면부 연골의 석회 화를 동반한 두꺼워진 이개 변형이 있는 대부분의 경우에 유 용하게 사용할 수 있는 방법으로 판단된다. 다만, 석회화 병 변이 이개 후면에 주로 있을 경우에는 후이개 접근법 또는 병 변에 직전 절개를 넣는 방법을 고려해야 할 것이다.

\section{Author Contribution}

Conceptualization: Shi Nae Park. Data curation: Shi Nae Park, Ji hyung Lim. Visualization: Ji hyung Lim, Jae Sang Han. Writingoriginal draft: Ji hyung Lim, Jae Sang Han. Writing-review \& editing: Shi Nae Park, Yeonji Kim.

\section{ORCIDs}

Shi Nae Park

https://orcid.org/0000-0002-7614-9413

Ji hyung Lim https://orcid.org/0000-0003-4828-1510 Jae Sang Han https://orcid.org/0000-0001-7728-1232 Yeonji Kim https://orcid.org/0000-0003-3127-5827

\section{REFERENCES}

1) Greywoode JD, Pribitkin EA, Krein H. Management of auricular hematoma and the cauliflower ear. Facial Plast Surg 2010;26(6): 451-5.

2) Pandya NJ. Experimental production of "cauliflower ear" in rabbits. Plast Reconstr Surg 1973;52(5):534-7.

3) Ohlsén L, Skoog T, Sohn SA. The pathogenesis of cauliflower ear. An experimental study in rabbits. Scand J Plast Reconstr Surg 1975;9(1):34-9.

4) O'Donnell BP, Eliezri YD. The surgical treatment of traumatic hematoma of the auricle. Dermatol Surg 1999;25(10):803-5.

5) Im GJ, Chae SW, Choi J, Kim YS, Kim WJ, Jung HH. Intralesional steroid injection for the management of otohematoma. Otolaryngol Head Neck Surg 2008:139(1):115-9.

\section{Acknowledgments}

None. 